\title{
Larval Performance in the Context of Ecological Diversification and Speciation in Lycaeides Butterflies
}

\author{
Cynthia F. Scholl, ${ }^{1}$ Chris C. Nice, ${ }^{2}$ James A. Fordyce, ${ }^{3}$ \\ Zachariah Gompert, ${ }^{4}$ and Matthew L. Forister ${ }^{1}$
}

${ }^{1}$ Department of Biology, University of Nevada, Reno, NV 89557, USA

${ }^{2}$ Department of Biology, Population and Conservation Biology Program, Texas State University, San Marcos, TX 78666, USA

${ }^{3}$ Department of Ecology and Evolutionary Biology, University of Tennessee, Knoxville, TN 37996, USA

${ }^{4}$ Department of Botany, Program in Ecology, University of Wyoming, Laramie, WY 82071, USA

Correspondence should be addressed to Cynthia F. Scholl, cynthia.scholl@gmail.com

Received 26 July 2011; Accepted 29 November 2011

Academic Editor: Rui Faria

Copyright ( $) 2012$ Cynthia F. Scholl et al. This is an open access article distributed under the Creative Commons Attribution License, which permits unrestricted use, distribution, and reproduction in any medium, provided the original work is properly cited.

\begin{abstract}
The role of ecology in diversification has been widely investigated, though few groups have been studied in enough detail to allow comparisons of different ecological traits that potentially contribute to reproductive isolation. We investigated larval performance within a species complex of Lycaeides butterflies. Caterpillars from seven populations were reared on five host plants, asking if host-specific, adaptive larval traits exist. We found large differences in performance across plants and fewer differences among populations. The patterns of performance are complex and suggest both conserved traits (i.e., plant effects across populations) and more recent dynamics of local adaptation, in particular for L. melissa that has colonized an exotic host. We did not find a relationship between oviposition preference and larval performance, suggesting that preference did not evolve to match performance. Finally, we put larval performance within the context of several other traits that might contribute to ecologically based reproductive isolation in the Lycaeides complex. This larger context, involving multiple ecological and behavioral traits, highlights the complexity of ecological diversification and emphasizes the need for detailed studies on the strength of putative barriers to gene flow in order to fully understand the process of ecological speciation.
\end{abstract}

\section{Introduction}

Understanding the processes underlying diversification is a central question in evolutionary biology. Lineages diversify along multiple axes of variation, including morphological, physiological, and ecological traits. With respect to diversification in ecological traits, many recent studies have found that ecological niches can be highly conserved from a macroevolutionary perspective [1-3]. In other words, closely related species tend to utilize similar resources or occupy similar environments. In contrast, the field of ecological speciation suggests that ecological traits can evolve due to disruptive selection and drive the process of diversification [4-8]. In herbivorous insects, evolution in response to habitat or host shifts is often thought to be a first step in the evolution of reproductive isolation $[9,10]$. In most well-studied systems, although exceptions exist $[6,11]$, niche conservatism and niche evolution are often characterized by a small number of ecological traits, such as habitat preference or physiological performance [12-14]. To understand the causes and consequences of evolution in ecological traits, more studies are needed of groups in which diversification is recent or ongoing and multiple ecological traits are studied. The study of multiple traits is particularly important for our understanding of ecological speciation. For example, it has been suggested that weak selection acting on a multifarious suite of traits could be as important for speciation as strong selection acting on a single ecological trait [15].

The butterfly genus Lycaeides (Lycaenidae) includes a complex of taxa in North America that has been the focus of studies investigating the evolution and ecology of host use, mate choice, and genitalic morphology, among other 
subjects [16-19]. In the context of diversification, this group is interesting because hybridization has been documented among multiple entities, with a variety of consequences $[20,21]$, including the formation of at least one hybrid species in the alpine of the Sierra Nevada mountains [22]. The Lycaeides taxa in western North America (specifically L. idas, L. melissa, and the hybrid species) differ in many traits, some of which have been implicated in the evolution of ecological reproductive isolation in this system. For example, there is variation in the strength of host preference, which is often linked to reproductive isolation in herbivorous insects that mate on or near their host plants, as Lycaeides do [17]. There are also potentially important differences in mate preference, phenology, and egg adhesion $[16,23]$. The latter trait is interesting with respect to the evolution of the hybrid species, which lacks egg adhesion $[22,23]$. The eggs of the hybrid species fall from the host plants. This is presumed to be an adaptation to the characteristics of the alpine plants, for which the above-ground portions senesce and are blown by the wind away from the site of next year's fresh growth (thus eggs that fall off are well positioned for feeding in the spring). Since the eggs of lower-elevation Lycaeides taxa do adhere to hosts, this trait could serve as a barrier to gene flow with respect to individuals immigrating from lower elevations.

Our state of knowledge for Lycaeides is unusual for wellstudied groups of herbivorous insects in that we know a great deal about a diversity of traits, as discussed above, but we have not heretofore investigated larval performance across taxa in the context of ecological speciation, which is often one of the first traits studied in other insect groups [24]. This study has two goals, first to investigate larval performance and then to put this information in the context of other already-studied traits to investigate which traits might be important for reducing gene flow between populations and species in this system. We have focused on performance of caterpillars from both L. idas and L. melissa populations as well as from populations of the hybrid species. Beyond the inclusion of the hybrid taxon, of added interest is the fact that L. melissa has undergone a recent expansion of diet, encompassing exotic alfalfa (Medicago sativa) as a larval host plant across much of its range. Thus we are able to investigate variation in the key ecological trait of larval performance across multiple levels of diversification, including the differentiation of L. idas and L. melissa, the formation of a hybrid species, and a host expansion that has occurred within the last two hundred years $[19,22,25]$.

Using individuals from two L. idas, three L. melissa, and two hybrid species populations, we conducted reciprocal rearing experiments using all five of the host species found at these focal populations. We assessed larval performance by examining survival, time to emergence (eclosion), and adult weight, and by comparing survival curves from different populations on the different plants. For each population, we contrasted larval performance on a natal host to performance on the plants of other populations. Higher larval performance on natal host plants would support the hypothesis of local adaptation to host plant species. In the second part of the paper, these results are discussed both within the light of local adaptation in a diversifying group and also within the context of possible reproductive isolation related to variation in ecological traits.

\section{Methods}

Two of our focal taxa, L. idas and L. melissa, are widely distributed across western North America. Our study focused on populations of these two species and the hybrid species in northern California and Nevada (Figure 1). In this area, L. idas is found on the west slope of the Sierra Nevada, $L$. melissa is found on the eastern side, and the hybrid species is only found in the alpine zone. Lycaeides species use a variety of plants in the pea family, Fabaceae, as hosts, although (with few exceptions) specific Lycaeides populations generally utilize a single host plant species. The two L. idas populations studied were Yuba Gap (YG), which uses Lotus nevadensis as a host, and Leek Springs (LS) which uses the host Lupinus polyphyllus (Table 1). Both populations of the hybrid species, Mt. Rose (MR) and Carson Pass (CP), use Astragalus whitneyi. At Washoe Lake (WL), L. melissa uses the native host Astragalus canadensis; at Beckwourth Pass (BP), butterflies use both A. canadensis and alfalfa, Medicago sativa; at Goose Lake (GLA), the only available host is alfalfa (Table 1).

Lycaeides idas and the hybrid species are univoltine, while L. melissa populations have at least three generations per year. Eggs from the univoltine populations have to be maintained under winter conditions (i.e., cold temperatures and darkness) in the lab for experiments in the following spring. Females and eggs from univoltine populations were collected in the summer of 2008 to be reared in the summer of 2009, while L. melissa females and eggs were collected during the 2009 summer. Females were collected from the L. idas and hybrid species populations (32 from Yuba Gap, 50 from Leek Springs, 45 from Carson Pass, and 40 from Mt. Rose) and caged individually or in small groups with host plants for a period of three days after which eggs were collected. Eggs were washed with a dilute (2\%) bleach solution and held over the winter at $4-6^{\circ} \mathrm{C}$. Eggs were removed from cold storage on May 27th, 2009, and the majority hatched within several hours. The number of caterpillars hatching synchronously required that the larvae be moved in groups of twenty to standard-sized petri dishes (100 mm diameter) with fresh plant material on the 27 th and 28th. On the 29th and 30th of May, the groups of twenty were split into three dishes each containing three to seven individuals. An average of 6 caterpillars was added to 9 dishes per treatment (plant/population combination); in some cases fewer (but not less than three) caterpillars were added per dish to try to maximize the number of dishes, which is the unit of replication (see below). Once all the larvae in a petri dish reached the 3rd or 4th instar they were moved to larger petri dishes ( $170 \mathrm{~mm}$ diameter). These groups of individuals were considered a "rearing dish," and dish was used as a random factor in statistical analyses (see below).

Females and eggs from the three L. melissa populations were collected following similar protocols (though without the necessity of overwintering). Seventeen females were 


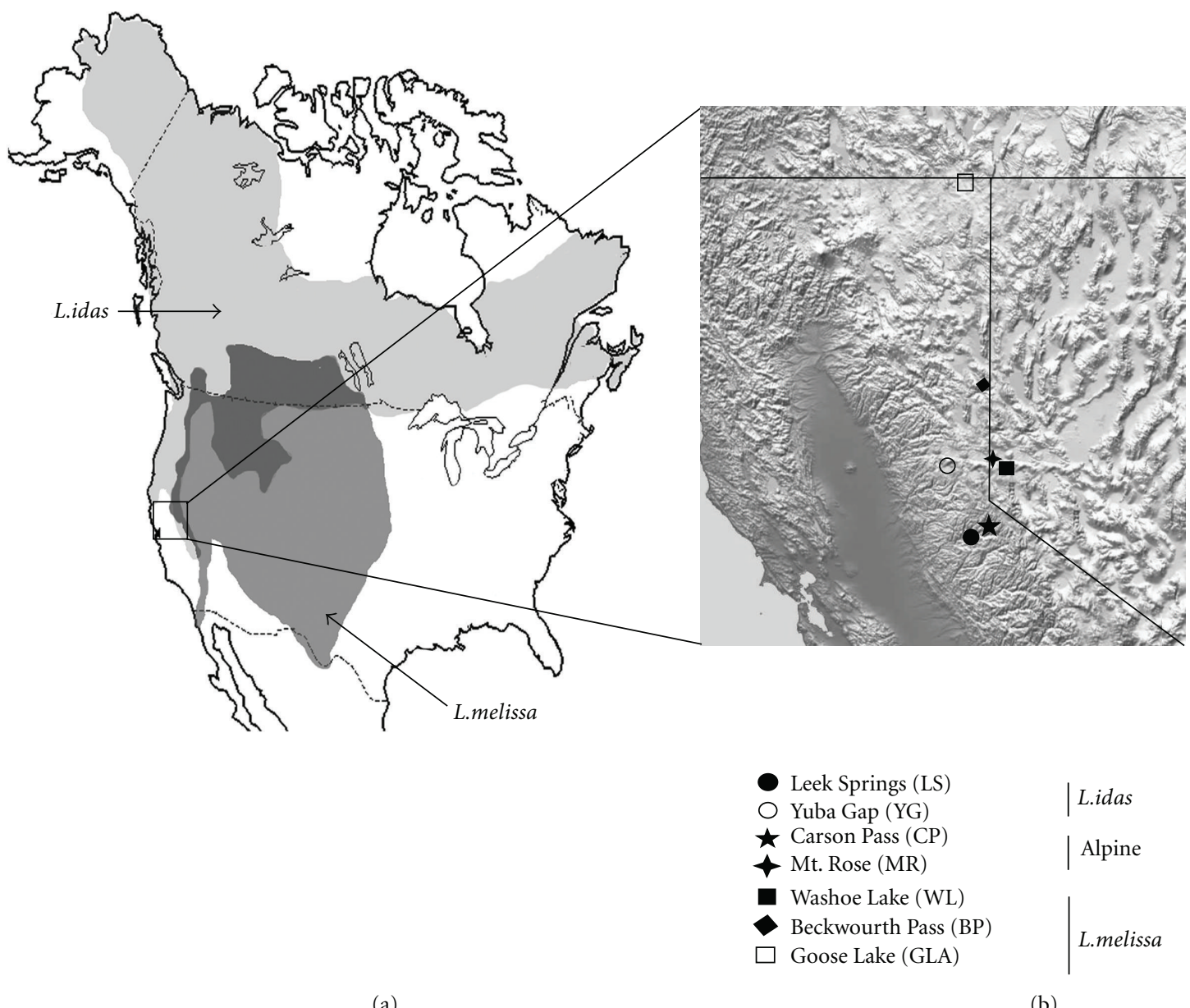

(a)

(b)

Figure 1: (a) Ranges of L. idas and L. melissa across North America, darker shaded regions correspond to ranges of overlap, which includes alpine populations of the hybrid species considered here (CP and MR). (b) Map of sampled Lycaeides populations in Northern California and Nevada, USA. Symbols correspond to populations and taxa.

TABLE 1: Locations of populations (see also Figure 1) and hosts associated with the seven populations studied.

\begin{tabular}{lccc}
\hline Taxon & Location & Latitude/longitude & Host \\
\hline \multirow{2}{*}{ L. idas } & Leek Springs (LS) & $38^{\circ} 38^{\prime} 8^{\prime \prime} \mathrm{N} / 120^{\circ} 14^{\prime} 25^{\prime \prime} \mathrm{W}$ & Lupinus polyphyllus \\
& Yuba Gap (YG) & $39^{\circ} 19^{\prime} 24^{\prime \prime} \mathrm{N} / 120^{\circ} 35^{\prime} 60^{\prime \prime} \mathrm{W}$ & Lotus nevadensis \\
Hybrid species & Carson Pass (CP) & $38^{\circ} 42^{\prime} 28^{\prime \prime} \mathrm{N} / 120^{\circ} 0^{\prime} 28^{\prime \prime} \mathrm{W}$ & Astragalus whitneyi \\
& Mt. Rose (MR) & $39^{\circ} 19^{\prime} 21^{\prime \prime} \mathrm{N} / 119^{\circ} 55^{\prime} 47^{\prime \prime} \mathrm{W}$ & Astragalus whitneyi \\
L. melissa & Washoe Lake (WL) & $39^{\circ} 13^{\prime} 59^{\prime \prime} \mathrm{N} / 119^{\circ} 46^{\prime} 46^{\prime \prime} \mathrm{W}$ & Astragalus canadensis \\
& Beckwourth Pass (BP) & $39^{\circ} 46^{\prime} 55^{\prime \prime} \mathrm{N} / 120^{\circ} 4^{\prime} 23^{\prime \prime} \mathrm{W}$ & Astragalus canadensis and Medicago sativa \\
\hline
\end{tabular}

collected from Beckwourth Pass during the last week of June, 27 were collected from Goose Lake the third week of July, and 14 were collected from Washoe Lake the last week of July. For these populations, larvae were added to standard-sized petri dishes in groups of four to six individuals as soon as the eggs hatched. Again, caterpillars were transferred to a large petri dish once all the individuals in a dish reached the $3 \mathrm{rd}$ or 4 th instar.
Larvae from each population were reared on all five plants, Astragalus canadensis, Astragalus whitneyi, Lotus nevadensis, Lupinus polyphyllus, and Medicago sativa, with individual rearing dishes being assigned exclusively to a single plant throughout development. Caterpillars in the wild consume both vegetative and reproductive tissues, but only leaves were used in this study, as flowers would be difficult to standardize across plants (not being available synchronously 
for most species). For a study of this kind, ideally all plant material to be used in rearing would be collected from focal locations (where butterflies are flying) or grown in a common environment. However, many of these species are not easily propagated, and moreover our focal locations are widely dispersed geographically; these factors necessitated some compromise in collecting some of the plants. A. canadensis cuttings were obtained at the site of the butterfly populations at Beckwourth Pass and Washoe Lake and from the greenhouse (plants were grown from seeds collected at Washoe Lake). Astragalus whitneyi was collected from the site of the Mt. Rose hybrid species population and on a hillside adjacent to Carson Pass $\left(38^{\circ} 42^{\prime} 23^{\prime \prime} / 120^{\circ} 00^{\prime} 23^{\prime \prime}\right)$. All Lotus nevadensis were collected from Yuba Gap (YG). The only case in which plant material was collected from a site where the butterfly is not found is Lupinus polyphyllus. These plants were collected off I-80 at the Soda Springs exit $\left(39^{\circ} 19^{\prime} 29^{\prime \prime} / 120^{\circ} 23^{\prime} 25^{\prime \prime}\right)$ and seven miles north of Truckee CA, off State Route $89\left(39^{\circ} 25^{\prime} 59^{\prime \prime} / 120^{\circ} 12^{\prime} 13^{\prime \prime}\right)$. Medicago sativa was obtained from Beckwourth Pass (BP) and from plants grown in the greenhouse with seeds from BP. $M$. sativa was also collected from south of Minden, NV on State Route $88\left(38^{\circ} 48^{\prime} 60^{\prime \prime} / 119^{\circ} / 46^{\prime} / 46^{\prime \prime}\right)$ and off of California State Route 49 in Sierra Valley, CA $\left(39^{\circ} 38^{\prime} 35^{\prime \prime} / 120^{\circ} 23^{\prime} 10^{\prime \prime}\right)$. Plant material was kept in a refrigerator and larvae were fed fresh cuttings whenever the plant material in petri dishes was significantly reduced or wilted, which was approximately every two to seven days. Each time caterpillars were given fresh plant material, the number of surviving caterpillars was recorded along with the date. All dishes were kept at room temperature, $20^{\circ}$ to $23^{\circ}$ Celsius, on lab benches. Newly emerged adults were individually weighed to the nearest $0.01 \mathrm{mg}$ on a Mettler Toledo XP26 microbalance and sex was recorded.

2.1. Analyses. The strengths of our experiment were that we reared a large number of individuals from multiple taxa across five plants, but a weakness of our design was that not all rearing could be done simultaneously. As discussed further below, flowers were not included in the rearing, and plant material was collected from most but not all focal populations. Experiments were conducted in two phases, first involving the populations of the hybrid species and $L$. idas, being reared together and earlier in the spring, and second involving the three low-elevation $L$. melissa populations being reared later in the summer. This division into two rearing groups was largely a consequence of being constrained by the total number of caterpillars that could be handled and reared in the lab at any one time. Considering the possibility that phenological variation in plants could have implications for larval performance, we conducted analyses separately for the three butterfly species. Postemergence adult weight, time to emergence as adult, and survival to adult were recorded. Mortality (reflected in the survival data) included death associated with caterpillars that died while developing, individuals that pupated but failed to emerge, and disease; we did not distinguish between these sources of mortality. Data were standardized ( $Z$ transformed) within populations to facilitate comparisons among populations and taxa that may have inherent differences, such as in size or in development time. $Z$ scores were used in analyses described below unless otherwise noted.

Dish was considered the unit of replication, thus percent survival was calculated per dish. For analyses of adult weight and time to emergence, dish was used as a random factor. Percent survival was analyzed using analysis of variance (ANOVA) with plant, population and the interaction between the two as predictor variables. Time to emergence and adult weight were both analyzed with ANOVA, using population, plant, the interaction between the two and sex as predictor variables, along with dish as a random factor nested within plant and population. For all of these analyses, ANOVA was performed a second time without the plant/population interaction if it was not significant at $\alpha<$ 0.05 . These analyses were performed using JMP software version 8.0.2 (SAS Institute).

Differences in survival were also investigated by generating and comparing survival curves. To create survival curves, individual caterpillars were assumed to be alive until the date they were found dead. Rather than analyzing survival curves on an individual-dish basis (where sample sizes were small), the number of individuals surviving on a given day was calculated for each plant/population combination, giving one curve per combination, as is often done in survival analysis [26]. Survival curves were generated in R (2.12.2) using the packages splines and survival. The shapes of the curves were investigated within population using the packages MASS and fitdistrplus. Weibull distributions are commonly used to model survival using two parameters, shape and scale. The shape parameter measures where the inflection point occurs or practically whether individuals are lost more at the beginning or end of a given time period, and the scale parameter characterizes the depth of the curve. We estimated the two Weibull parameters, shape and scale, that characterized the fitted curves using maximum likelihood. One-thousand bootstrap replicates were then used to generate $95 \%$ confidence intervals for the shape and scale parameters, so that they could be compared across plants within a given population.

\section{Results}

We began the larval performance experiments with 2040 caterpillars in 357 dishes. Average survival to eclosion across all experiments was $23.4 \%$. In general, differences in larval performance among plants were greater than differences between populations, which can be seen both in Figure 2 and also by comparing variation partitioned by plants and population in Table 2. For example, survival was highest on Lotus nevadensis across all populations for all three taxa, with an average survival of 56.5\% (survival on Lupinus polyphyllus was comparable for two of the three L. melissa populations). Survival on alfalfa was consistently the lowest of any plant across populations: only two caterpillars survived to eclosion (Figures 2 and 3). Because survival was so low on alfalfa, it was excluded from most analyses and figures. The inferior nature of alfalfa as a host plant is consistent with previous studies, particularly when caterpillars do not have access to 


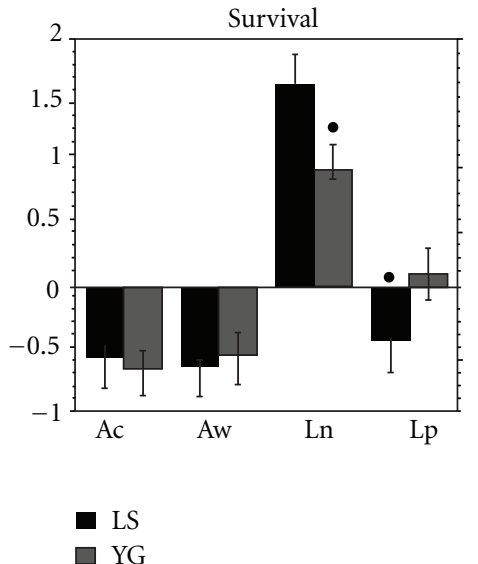

(a)

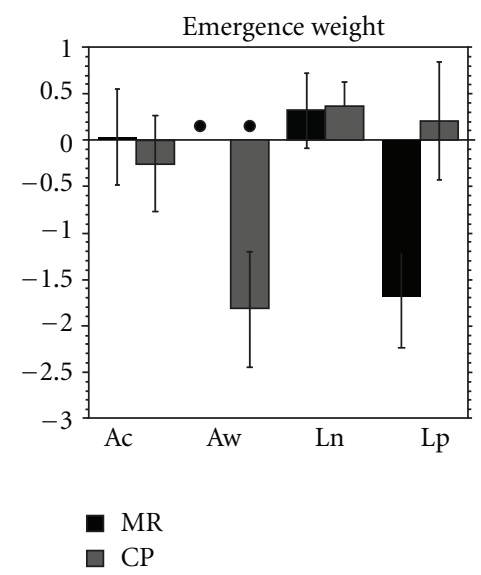

(d)

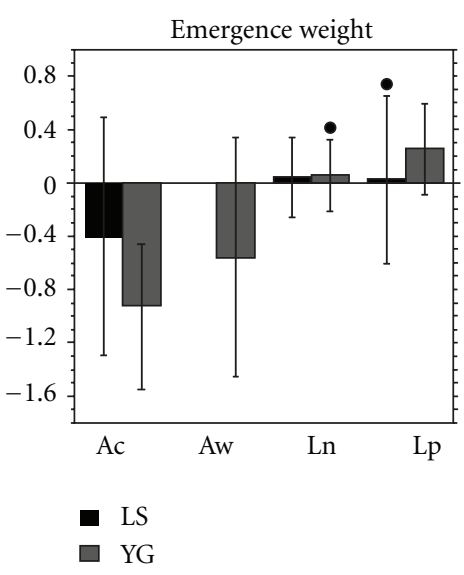

(b)

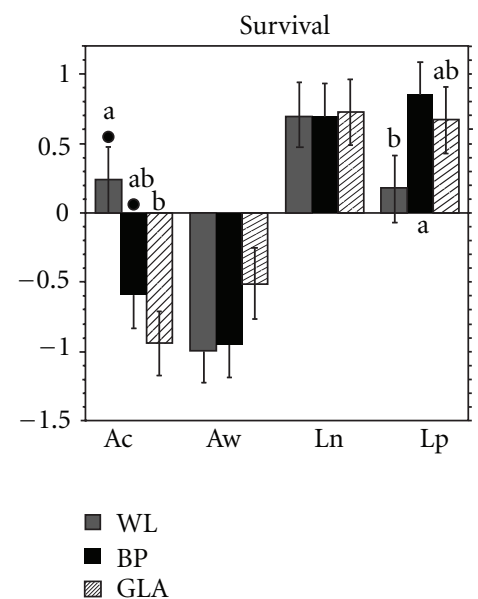

(e)

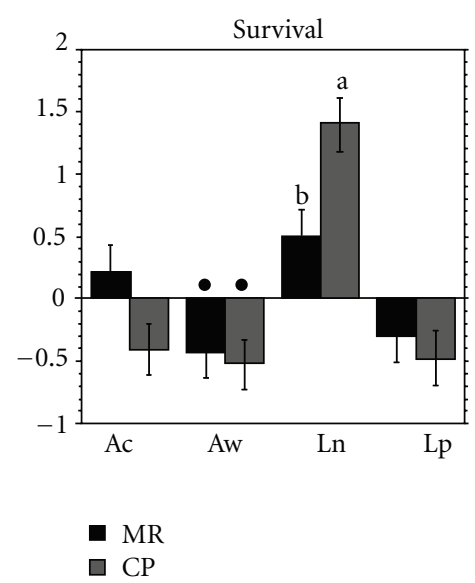

(c)

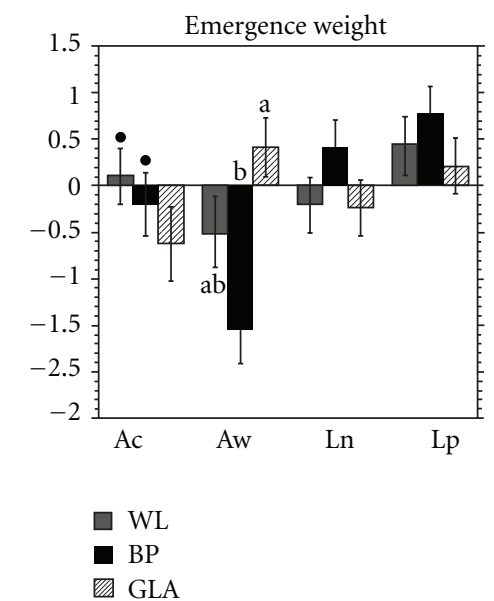

(f)

FIgURE 2: Survival and emergence weights from rearing experiments: (a and b) L. idas, (c and d) hybrid species, (e and f) L. melissa. Values are standardized ( $Z$ transformed). Shading of bars indicates plant species; see legends and Figure 1 for population locations. See Table 2 for associated model details, including plant and population effects. Significant differences $(P<0.05)$ for population effects within plants are indicated here with small letters near bars. Black dots identify natal host associations for each population. Host plant abbreviations as follows. Ac; Astragalus canadensis; Aw; Astragalus whitneyi; Ln; Lotus nevadensis; Lp; Lupinus polyphyllus. Results from alfalfa, M. sativa, are not shown here because survival was very low; see main text for details.

flowers and flower buds. When flowers have been included in performance experiments, survival of L. melissa on alfalfa and A. canadensis was equal, although those individuals reared on alfalfa were significantly smaller adults [19].

Plant and the interaction between plant and population were significant predictors of survival for L. idas, L. melissa, and the hybrid species (Table 2). Within taxa, there were differences among populations on certain plants. For example, survival for L. idas on Lotus nevadensis was greater for LS compared to YG, but the pattern was reversed for the host Lupinus polyphyllus (Figure 2); in other words, each population had higher survival on the natal host of the other population. A different pattern can be seen across populations of L. melissa on Astragalus canadensis, where survival was highest for individuals from $W L$, a population whose natal host is A. canadensis. L. melissa survival on A. canadensis was lowest for GLA, which is a population associated with the exotic host alfalfa, and survival on A. canadensis is intermediate for BP, where both A. canadensis and alfalfa are utilized. Thus host use by L. melissa populations predicts variation in larval performance. Effects of plant and population were generally not as pronounced for either adult weight or time to emergence (for $L$. idas, the only significant predictors of adult weight were dish and sex); exceptions to this include the significant population by plant interaction for adult weight of $L$. melissa. As with survival, $L$. melissa performance (adult weight) was greater on $A$. canadensis for the population that is associated with that plant, WL (Figure 2(f)).

Consistent with results for survival to emergence as an adult, survival curves through time also showed pronounced differences among plants (Figure 3; Table 4). For example, the Weibull scale parameter for alfalfa was generally different compared to the other plants, reflecting early and pervasive mortality for individuals reared on that plant. Most but not 
TABLE 2: Results from analyses of variance for the three measures of performance: percent survival, adult weight, and time to emergence. In all cases dish was used as the unit of replication. Most population/plant combinations had 9 dishes, except for the following: YG/Ac 12 dishes, YG/Ln 12 dishes, YG/Lp 12 dishes, YG/Ms 12 dishes, and all plant combinations for CP and MR had 12 dishes. The total number of dishes was 357.

\begin{tabular}{|c|c|c|c|}
\hline & SS & $F$ Ratio $_{\mathrm{df}}$ & $P$ \\
\hline \multicolumn{4}{|l|}{ Survival L. idas } \\
\hline Plant & 48.62 & $42.02_{3,73}$ & $<0.0001$ \\
\hline Population & 0.02 & $0.06_{1,73}$ & 0.81 \\
\hline Plant $\times$ population & 4.00 & $3.46_{3,73}$ & 0.02 \\
\hline \multicolumn{4}{|l|}{ Survival hybrid species } \\
\hline Plant & 30.93 & $16.33_{3,88}$ & $<0.0001$ \\
\hline Population & 0.00 & $0.00_{1,88}$ & 1.00 \\
\hline Plant $\times$ population & 7.50 & $3.96_{3,88}$ & 0.01 \\
\hline \multicolumn{4}{|l|}{ Survival L. melissa } \\
\hline Plant & 44.95 & $29.32_{3,96}$ & $<0.0001$ \\
\hline Population & 0.03 & $0.03_{2,96}$ & 0.97 \\
\hline Plant $\times$ population & 9.99 & $3.26_{6,96}$ & 0.006 \\
\hline \multicolumn{4}{|l|}{ Adult weight $L$. idas } \\
\hline Plant & 2.11 & $0.52_{3,33.47}$ & 0.67 \\
\hline Population & 0.49 & $0.14_{1,19.38}$ & 0.71 \\
\hline Dish (plant, population) random & 47.78 & $4.04_{26,74.00}$ & $<0.0001$ \\
\hline Sex & 10.81 & $11.87_{2,74.00}$ & $<0.0001$ \\
\hline \multicolumn{4}{|l|}{ Adult weight hybrid species } \\
\hline Plant & 7.25 & $2.81_{3,48.09}$ & 0.049 \\
\hline Population & 0.53 & $0.61_{31,48.45}$ & 0.44 \\
\hline Dish (plant, population) random & 14.90 & $0.74_{20,30.00}$ & 0.76 \\
\hline Sex & 1.29 & $1.28_{1,30.00}$ & 0.27 \\
\hline \multicolumn{4}{|l|}{ Adult weight $L$. melissa } \\
\hline Plant & 21.22 & $7.25_{3,132.13}$ & 0.0002 \\
\hline Population & 8.62 & $4.54_{2,154.10}$ & 0.01 \\
\hline Dish (plant, population) random & 89.56 & $1.44_{84,217.00}$ & 0.02 \\
\hline Plant $\times$ population & 11.24 & $15.15_{1,217.00}$ & 0.0001 \\
\hline Sex & 25.93 & $4.39_{6,126.13}$ & 0.0005 \\
\hline \multicolumn{4}{|l|}{ Time to emergence $L$. idas } \\
\hline Plant & 20.32 & $8.91_{3,59.17}$ & $<0.0001$ \\
\hline Population & 0.69 & $0.99_{1,4.11}$ & 0.37 \\
\hline Dish (plant, population) random & 19.34 & $0.94_{26,75.00}$ & 0.55 \\
\hline Sex & 3.87 & $2.45_{2,75.00}$ & 0.09 \\
\hline \multicolumn{4}{|l|}{ Time to emergence hybrid species } \\
\hline Plant & 5.30 & $3.28_{2,25.82}$ & 0.05 \\
\hline Population & 0 & $0_{0,28.00}$ & 1.00 \\
\hline Dish (plant, population) random & 16.06 & $0.95_{20,28.00}$ & 0.54 \\
\hline Sex & 1.20 & $1.41_{1,28.00}$ & 0.25 \\
\hline Plant $\times$ population & 6.04 & $3.61_{2,42.94}$ & 0.04 \\
\hline \multicolumn{4}{|l|}{ Time to emergence L. melissa } \\
\hline Plant & 9.36 & $2.41_{3,106.23}$ & 0.07 \\
\hline Population & 1.66 & $0.61_{2,99.01}$ & 0.54 \\
\hline Dish (plant, population) random & 125.50 & $2.34_{84,223.00}$ & $<0.0001$ \\
\hline Sex & 24.18 & $37.87_{1,223.00}$ & $<0.0001$ \\
\hline
\end{tabular}




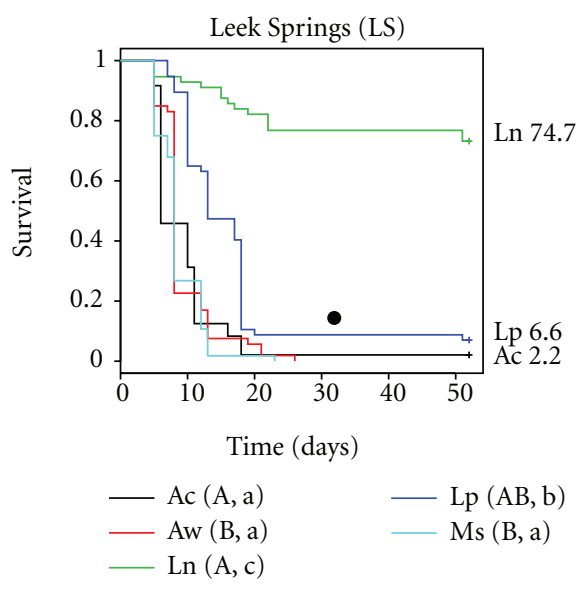

(a)
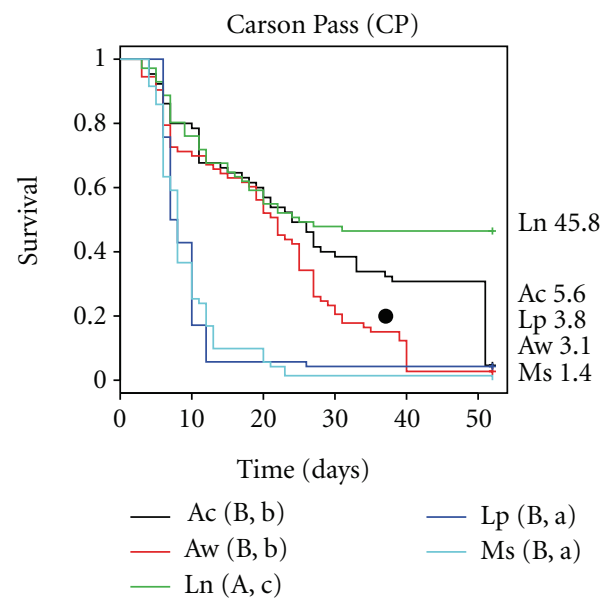

(c)

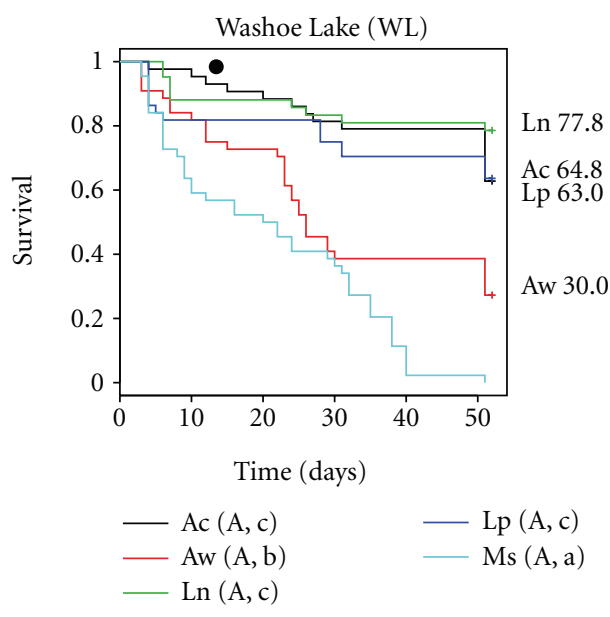

(e)

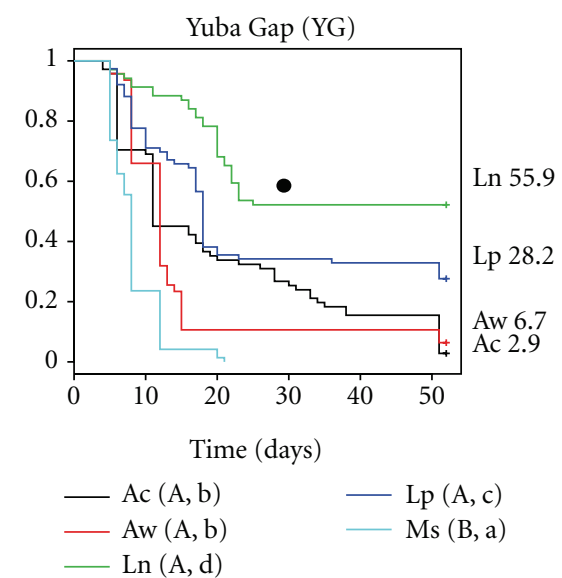

(b)

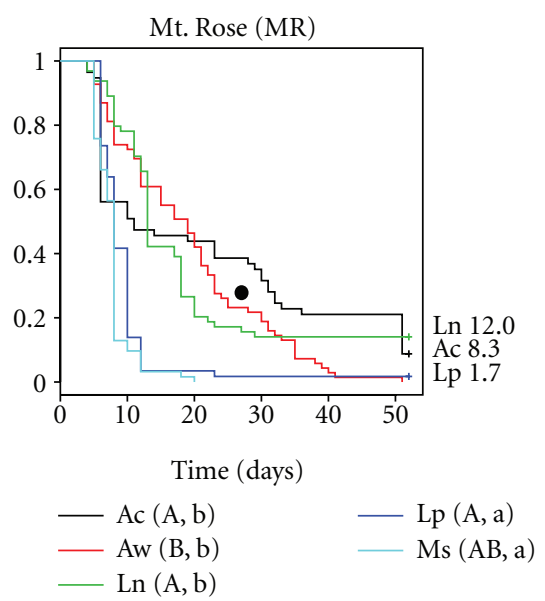

(d)

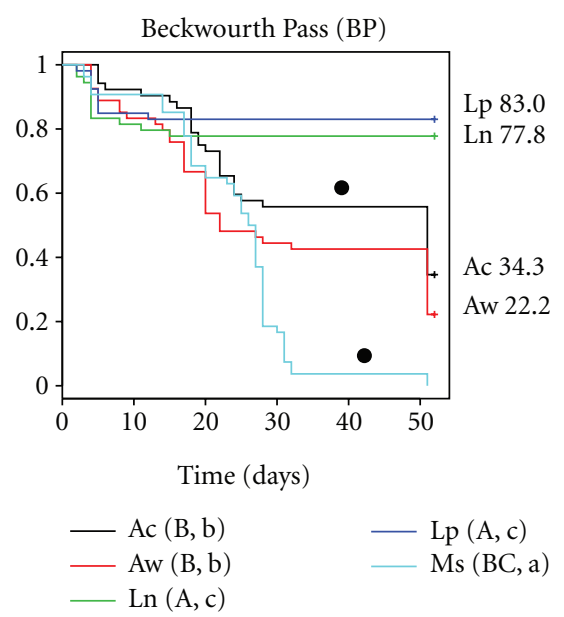

(f)

Figure 3: Continued. 


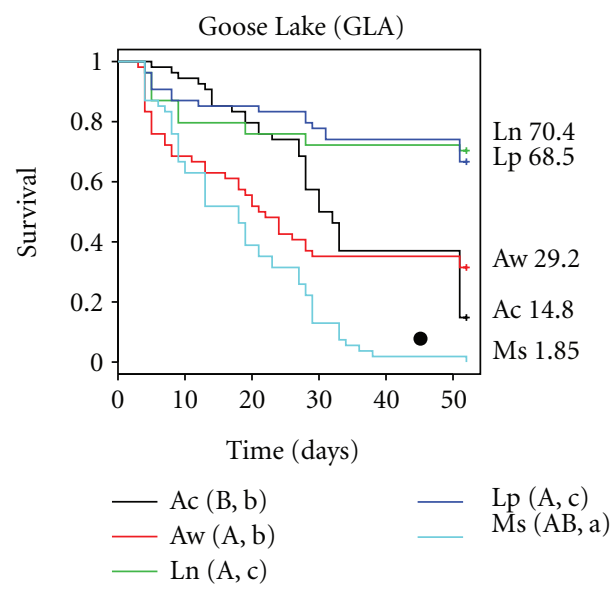

(g)

Figure 3: Survival curves for the seven populations studied. Colors indicate survival associated with a given plant; letters next to each plant in legends correspond to differences in the shape (upper case) and scale (lower case) of each curve indicated by nonoverlapping $95 \%$ confidence intervals from bootstrapped parameter values (see Table 4 for more details). Black dots indicate native host association for each population. Average, final survival is shown to the right of each graph for nonzero results. Plant abbreviations as follows. Ac; Astragalus canadensis; Aw; Astragalus whitneyi; Ln; Lotus nevadensis; Lp; Lupinus polyphyllus; Ms; Medicago sativa.

all mortality was manifested quite early in development, particularly for the alpine and $L$. idas populations across plants. Mortality was more evenly distributed through time for L. melissa on all plants. In some cases, patterns of survival vary among plants within populations, even when overall survival was low. For example, survival curves for CP drop much less rapidly for three plants, one of which is the natal host $A$. whitneyi and another is the congeneric A. canadensis (the third is $L$. nevadensis). For A. canadensis, it is interesting to note that across all populations there was a drop-off in survival near the end of development: many individuals made it to the pupal stage, but failed to emerge, perhaps suggesting a subtle nutritional challenge for successful completion of development presented by that plant.

\section{Discussion}

The reciprocal rearing experiment detected strong host plant effects and limited evidence of local adaptation to natal host plant species in the Lycaeides species complex. For example, development on L. nevadensis (the host of the $L$. idas population at YG) resulted in relatively high survival throughout the experiment, while development on Medicago sativa (the exotic host of L. melissa at GLA and BP) led to extremely low survival in all cases. These plant effects that transcend populations could be indicative of larval traits (such as high survival on L. nevadensis) that are conserved in the group and are not particularly labile. Our results could be influenced by the use of leaves but not flowers in larval rearing. Previous work has shown that survival is improved on Medicago sativa for larvae that have access to flowers, but this is not true on Astragalus canadensis [19]. We do not know if flowers are or are not important for larvae developing on the other plants.
In general, the survival that we report (23.4\% throughout the experiment) could reflect the absence of flowers or other unfavorable lab conditions, and we do not at this time have life history data from the field for Lycaeides with which to compare our results. However, in interpreting results here and elsewhere (e.g., [19]), we make the assumption that lab experiments are informative with respect to relative performance across hosts. In other words, the consumption of $M$. sativa by Lycaeides caterpillars is associated with development into adults that are small relative to adults that develop on other plants. Without artifacts of lab rearing, it is possible that performance would generally be higher in the wild, but we would predict that performance on $M$. sativa would still be lower relative to performance on native hosts. An alternate possibility, which we cannot test at this time, is that lab rearing has plant-specific effects (i.e., M. sativa is a poor host only when used under artificial conditions).

For all the performance results, it is also important to note that phenological effects of changes in plant quality or suitability could be pronounced, but are not addressed by our experimental design. In particular, as noted above, our rearings were conducted in two phases due to logistical constraints: first including $L$. idas and populations of the hybrid species and second including all three L. melissa populations. This is not a completely unnatural situation, as L. idas and the hybrid species are univoltine, while L. melissa populations are multivoltine. Thus L. idas and hybrid species caterpillars are more likely to be exposed to only the early spring vegetation, as in our experiment. The consideration of phenological effects in plants is most relevant when comparing performance among butterfly taxa (e.g., the performance of $L$. melissa versus $L$. idas on a particular plant) but is less important when making comparisons within a taxon (e.g., the performance of L. melissa on different plant species). 
In contrast to the general result of strong plant effects across taxa and populations, one result suggestive of local adaptation is the performance (survival and adult weight) of L. melissa on the native host A. canadensis [27]. Performance was highest on the native for the population that utilizes that host in the wild and lowest for a population associated with the exotic host alfalfa. Performance on A. canadensis is intermediate for the population where both hosts are used. These results raise a number of possibilities, including a scenario in which genetic variants associated with higher performance on an ancestral host were lost in the transition to the exotic host, which could be a consequence of relaxed selection or a population bottleneck in the new environment. Another explanation could involve a change in gene regulation associated with performance, rather than a loss of alleles. In any event, the transition to the novel host has apparently not been accompanied by an increase in performance on alfalfa. One caveat to this conclusion is that the M. sativa used in experiments was collected at one of the focal locations (BP), but could not, for logistical reasons, be collected from GLA. The latter population (GLA) is the population associated only with $M$. sativa, thus the conclusion that performance has not increased following the colonization of the novel host could have been different if local plant material from that location had been used in experiments; however, we have found consistently low performance on $M$. sativa in other experiments [19], suggesting generality to the result of low performance on that plant.

Variation in host preference has previously been documented among populations of Lycaeides butterflies, with populations of the hybrid species in particular exhibiting strong preferences for their natal host, A. whitneyi $[17,22]$, relative to the hosts of other Lycaeides populations. However, we found low survival and low adult weights for individuals of the hybrid species reared on A. whitneyi (Figure 2). It is possible that laboratory conditions were a poor reflection of appropriate abiotic conditions for the hybrid species individuals adapted to an alpine environment. It is also possible that other factors, such as the absence of flowers in experiments or induced defenses in leaves, could be important in A. whitneyi, which supported poor growth for larvae from all populations. In any event, the patterns of performance that we report are not consistent with an expected preference-performance paradigm for host shifts leading to the evolution of reproductive isolation [28]. Variation in both adult preference and larval performance is discussed further in the following section considering ecological traits and hypotheses relating traits to reproductive isolation.

4.1. Ecology and Diversification. Although many studies of herbivorous insects have focused on larval performance with respect to local adaptation and ecological speciation, populations of herbivorous insects (or of any organism) can of course differ in numerous ways, some related to resource use but also to other aspects of the environment. Nosil et al. [15] have suggested a number of scenarios in which multiple traits could be important in the evolution of reproductive isolation. In particular, natural selection acting on a single
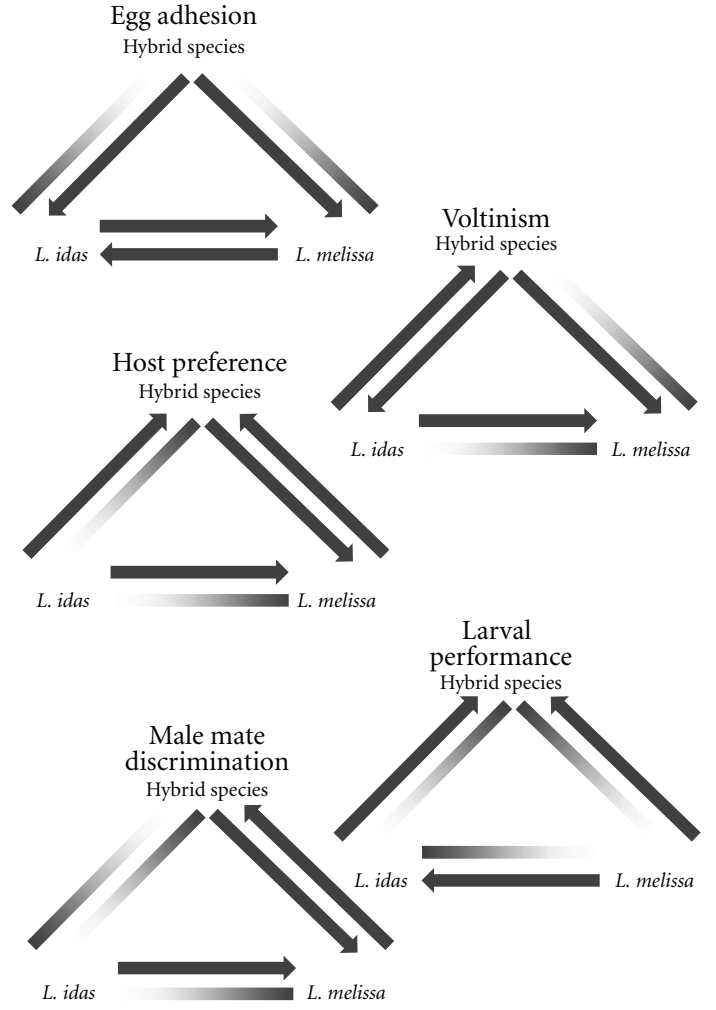

FIgURE 4: Summary of hypotheses relating ecological traits to reproductive isolation between taxa based on the current and past studies $[16,17,19,22,23]$. Arrows joining two taxa correspond to greater gene flow and those that are faded represent gene flow that could be prevented or reduced by a given trait. For details see text.

ecological trait or a single niche dimension could be important for initiating speciation, while the evolution of differences along multiple ecological axes might often be needed for complete reproductive isolation [15]. Multiple ecological axes could be different aspects of, for example, resource use $[29,30]$, or they could be more disparate traits, such as mate finding or predator avoidance. In either case, the idea is that selection along one axis might be insufficient for reproductive isolation, but selection acting along multiple axes might confer a high, overall level of reproductive isolation.

Considering the potential importance of multiple traits in ecological speciation, Figure 4 and Table 3 summarize information from this and other studies in Lycaeides and present hypotheses regarding multiple ecological and behavioral traits and how these might interact with ecological, reproductive isolating processes in this system. Specifically, Figure 4 explores hypotheses about reduced gene flow, represented by faded arrows, between the taxa due to the ecological differences of a given trait. For example, the model shown for egg adhesion posits that variation in adhesion could be a barrier to gene flow going from $L$. idas and $L$. melissa populations into populations of the hybrid species. $L$. idas and L. melissa females lay eggs that adhere to plants. As discussed above, the alpine host plants senesce and are blown from the area, thus removing any attached eggs from the site 
TABLE 3: Details of behavioral and ecological variation among taxa, specifically as variation relates to potential barriers to gene flow; see Figure 4 for a graphical interpretation of these traits in relation to gene flow. The descriptions of male mate discrimination refer to preferences of males for females of the other taxa. Details for larval performance refer to performance on the hosts of the other taxa relative to performance of the other taxa on those same plants.

\begin{tabular}{|c|c|c|c|}
\hline & L. idas & Hybrid species & L. melissa \\
\hline Egg adhesion & Yes & No & Yes \\
\hline Preference for natal host(s) & Moderate & High & Low to high \\
\hline Male mate discrimination & $\begin{array}{l}\text { Against L. melissa and hybrid } \\
\text { species }\end{array}$ & Against L. idas & None \\
\hline Voltinism & Univoltine & Univoltine & Multivoltine \\
\hline Larval performance & $\begin{array}{l}\text { Poor on hosts of L. melissa; } \\
\text { superior on host of hybrid } \\
\text { species }\end{array}$ & $\begin{array}{c}\text { Poor on hosts of both L. melissa } \\
\text { and L. idas }\end{array}$ & $\begin{array}{l}\text { Equivalent on hosts of } L \text {. idas } \\
\text { and superior on host of hybrid } \\
\text { species }\end{array}$ \\
\hline
\end{tabular}

Further information on specific behavioral and ecological variables (other than larval performance, reported here) can be found as follows: egg adhesion [23], preference for natal hosts [17, 19, 22], male mate discrimination [16], and voltinism [23].

of next-spring's fresh plant growth [23]. Differences in host preference might also affect patterns of gene flow between the species. The host of the hybrid species populations is readily accepted by ovipositing females from all Lycaeides examined thus far [17], thus it would likely be accepted by females from L. idas and L. melissa populations arriving at a population of the hybrid species. In contrast, the hosts of the L. idas populations are not preferred by females of either the hybrid species or L. melissa $[17,19]$. The arrows pointing towards L. melissa assume the presence of only the native host $A$. canadensis, not the exotic $M$. sativa (excluding the exotic is a simplifying assumption for Figure 4, but also appropriate given that ecological diversification occurred before the recent introduction of alfalfa). Astragalus canadensis and $A$. whitneyi are equally acceptable for oviposition by hybrid species individuals (Forister, unpublished data), and we assume the same equivalence for $L$. idas (i.e., we assume $L$. idas females would readily accept $A$. canadensis, just as they do with $A$. whitneyi, thus an arrow without a barrier pointing from L. idas to L. melissa in the host preference diagram).

Similar to host preference, variation in male mate discrimination potentially presents barriers only between hybrid species and L. idas populations and between $L$. idas and L. melissa populations but not between hybrid species and L. melissa populations [17]. L. melissa males will readily approach either L. idas or females of the hybrid species, while L. idas males discriminate against females from the other two taxa, and hybrid species males discriminate against L. idas females. This behavioral variation among taxa, reported in Fordyce et al. [16], comes from choice tests involving dead and paper-model females presented in experimental arrays in the field. It is important to note that being a less-preferred mate is of course not the same as not being mated. In other words, a virgin L. melissa female that immigrated into an $L$. idas population might be a low-ranked mate for male L. idas relative to local females, but it is possible that she would eventually find a mate. However, the patterns of gene flow shown in Figure 4 are meant to be hypotheses for potential barriers to gene flow within a given trait. An L. melissa female immigrating into a population of the hybrid species would be mated more readily (and thus be more likely to contribute to the gene pool) relative to the dynamic just described (an L. melissa female arriving at an L. idas population). It is possible to imagine all of the traits depicted in Figure 4 being involved in either pre- or postzygotic isolation. For example, mate preference could act as just described on immigrant, virgin females, as in the immigrant inviability concept of Nosil et al. (2005) [31]. An alternative but similar scenario could involve the offspring of an immigrant; in this case, wing-pattern alleles (related to mate choice) would interact with mate choice in the next generation.

Variation in voltinism could affect gene flow from $L$. melissa into the other univoltine taxa. Because L. melissa populations are multivoltine, it is possible that an L. melissa female moving into populations of the other taxa would lay eggs that failed to diapause in habitats where the univoltine strategy is superior (such as in the alpine habitat where there is a short window for larval development [32]). Alternatively, diapause could be plastic, in which case the patterns of connectivity (hypothesized patterns of gene flow) pictured would be different.

We can now add larval performance to the suite of hypotheses linking ecology and gene flow in Lycaeides. In generating hypotheses relating larval performance to gene flow, we have used this criterion (focusing on survival, rather than adult weight, as the most straightforward metric of performance): if foreign larvae (i.e., the offspring of a recently arrived female) have lower survival on the local host relative to local individuals, we hypothesize a relative reduction in gene flow associated with performance. For gene flow between $L$. idas and L. melissa, the survival of $L$. idas larvae on the host of L. melissa is lower than the survival of $L$. melissa caterpillars on the same plant (see mean survival values in Figure 3). Interestingly in the context of hybrid speciation, our results suggest that gene flow from both $L$. idas and L. melissa would be unimpeded into populations of the hybrid species relative to the reverse, meaning that the two parental species had higher survival (relative to hybrid individuals) on the alpine host and that hybrid individuals had relatively inferior performance on the two parental species' hosts. Of course, this could be different if another trait, for example, egg adhesion, had a stronger effect or 
TABle 4: Survival curves for each host-population combination. A weibull distribution was fitted to each combination with 1000 bootstrap replicates. We report shape and scale parameters along with bootstrapped confidence intervals. Upper case and lower letters following shape and scale values correspond to 95\% confidence intervals that do not overlap (upper case letters for shape and lower case letters for scale) within populations based on the thousand bootstrapped replicates. See Figure 3 for graphical representation of survival curves.

\begin{tabular}{|c|c|c|c|c|c|}
\hline \multirow{2}{*}{$\begin{array}{l}\text { Population } \\
\text { CP }\end{array}$} & \multirow{2}{*}{$\frac{\text { Host }}{\text { Ac }}$} & \multicolumn{2}{|c|}{ Shape } & \multicolumn{2}{|l|}{ Scale } \\
\hline & & $1.47(1.25-1.75)$ & B & $31.16(26.22-36.37)$ & $\mathrm{b}$ \\
\hline $\mathrm{CP}$ & Aw & $1.61(1.35-1.97)$ & B & $23.53(20.27-27.09)$ & $\mathrm{b}$ \\
\hline $\mathrm{CP}$ & Ln & $0.82(0.71-0.95)$ & A & $63.75(42.86-110.98)$ & c \\
\hline $\mathrm{CP}$ & $\mathrm{Lp}$ & $1.38(1.12-2.62)$ & B & $11.73(9.61-14.66)$ & $\mathrm{a}$ \\
\hline $\mathrm{CP}$ & Ms & $1.67(1.34-2.42)$ & B & $10.86(9.41-12.76)$ & a \\
\hline $\mathrm{BP}$ & Ac & $1.50(1.17-2.01)$ & B & $51.38(41.18-64.28)$ & $\mathrm{b}$ \\
\hline $\mathrm{BP}$ & Aw & $1.31(1.07-1.61)$ & B & $39.56(31.44-50.49)$ & $\mathrm{b}$ \\
\hline $\mathrm{BP}$ & $\operatorname{Ln}$ & $0.44(0.38-0.52)$ & A & $1128.76(307.38-7477.83)$ & c \\
\hline $\mathrm{BP}$ & $\mathrm{Lp}$ & $0.44(0.39-0.51)$ & A & $2152.31(501.95-21856.68)$ & c \\
\hline $\mathrm{BP}$ & Ms & $2.65(2.00-4.07)$ & $\mathrm{BC}$ & $26.36(23.90-28.98)$ & a \\
\hline GLA & Ac & $2.154(1.76-2.69)$ & $\mathrm{B}$ & $40.31(34.73-46.00)$ & $\mathrm{b}$ \\
\hline GLA & Aw & $0.88(0.74-1.07)$ & A & $39.16(25.84-61.45)$ & $\mathrm{b}$ \\
\hline GLA & Ln & $0.66(0.53-0.86)$ & A & $236.85(115.08-750.35)$ & c \\
\hline GLA & Lp & $0.94(0.68-1.50)$ & A & $134.35(82.65-321.98)$ & c \\
\hline GLA & Ms & $1.70(1.44-2.10)$ & $\mathrm{AB}$ & $20.27(16.98-23.59)$ & a \\
\hline LS & Ac & $1.57(1.21-2.86)$ & A & $10.70(8.96-13.28)$ & $\mathrm{a}$ \\
\hline LS & Aw & $2.31(1.97-3.09)$ & B & $10.43(9.22-11.71)$ & $\mathrm{a}$ \\
\hline LS & Ln & $0.88(0.67-1.24)$ & A & 189.07 (104.65-511.29) & c \\
\hline LS & $\mathrm{Lp}$ & $1.58(1.33-2.17)$ & $\mathrm{AB}$ & $19.51(16.28-23.62)$ & $\mathrm{b}$ \\
\hline LS & Ms & $2.70(2.20-3.70)$ & B & $9.52(8.62-10.63)$ & $\mathrm{a}$ \\
\hline MR & Ac & $1.11(0.97-1.23)$ & A & $24.07(18.38-31.14)$ & $\mathrm{b}$ \\
\hline MR & Aw & $1.84(1.59-2.16)$ & B & $21.37(18.59-24.33)$ & $\mathrm{b}$ \\
\hline MR & Ln & $1.29(1.08-1.59)$ & A & $22.56(17.80-29.12)$ & $\mathrm{b}$ \\
\hline MR & Lp & $1.788(1.38-5.18)$ & A & $10.23(8.83-11.96)$ & $\mathrm{a}$ \\
\hline MR & Ms & $2.73(2.26-4.42)$ & $\mathrm{AB}$ & $8.54(7.71-9.45)$ & a \\
\hline $\mathrm{WL}$ & Ac & $1.65(1.03-3.29)$ & A & $82.61(62.56-145.41)$ & c \\
\hline WL & Aw & $1.20(0.92-1.57)$ & A & $41.69(31.24-56.54)$ & $\mathrm{b}$ \\
\hline WL & Ln & $0.77(0.57-1.38)$ & A & 302.19 (125.45-1912.44) & c \\
\hline WL & Lp & $0.77(0.56-1.24)$ & A & $144.13(79.93-404.52)$ & c \\
\hline WL & Ms & $1.43(1.22-1.89)$ & A & $22.96(18.23-28.27)$ & a \\
\hline YG & Ac & $1.29(1.17-1.45)$ & A & $22.20(18.23-27.03)$ & $\mathrm{b}$ \\
\hline YG & Aw & $1.34(1.12-1.88)$ & A & $17.23(13.41-22.86)$ & $\mathrm{b}$ \\
\hline YG & Ln & $1.05(0.89-1.21)$ & A & $71.74(50.50-111.48)$ & $\mathrm{d}$ \\
\hline YG & Lp & $1.07(0.94-1.23)$ & A & $36.16(27.35-49.30)$ & c \\
\hline YG & Ms & $2.45(2.12-3.32)$ & $\mathrm{B}$ & $9.25(8.30-10.29)$ & a \\
\hline
\end{tabular}

acted before larval performance in restricting gene flow (see $[6,11]$ for examples of the complexities of estimating components of reproductive isolation associated with a suite of traits). We stress that these are hypotheses that bear further investigation, as we know that larval performance is complex, being affected not only by variation in host quality (i.e., the availability of flowers [19]) but also by the presence of mutualistic ants and natural enemies [33].

\section{Conclusion}

We conducted a performance experiment for seven populations from three species within the Lycaeides species complex, L. idas, L. melissa, and the hybrid species, on five different plants. Our primary results include large plant effects, with $L$. idas hosts being generally superior for larval development and the exotic host of L. melissa being extremely poor, both 
for L. melissa and the other taxa. In general, there is little evidence of local adaptation in these performance data. This conclusion is perhaps consistent with the fact that these butterfly taxa are associated with multiple hosts throughout their geographic ranges. Thus gene flow could limit local adaptation to any particular plant species. As a consequence, variation in larval performance across multiple hosts is unlikely to be the dominant mechanism of reproductive isolation between populations and taxa.

Our results (including some evidence for local adaptation among L. melissa populations for their native host, $A$. canadensis) together with previously published data $[16,17$, $19,22,23$ ] were integrated to build a hypothetical model relating ecology to reproductive isolation and diversification in Lycaeides. The model presented in Figure 4 describes a system that is well poised for a test of the "multifarious selection" hypothesis [15]. One hypothesis that can be generated from Figure 4 is that there might not be one single trait that could act as a barrier to gene flow between all three taxa, and most traits might only act to reduce gene flow asymmetrically. For example, egg adhesion could affect gene flow from both $L$. idas and L. melissa into the hybrid species, but would not necessarily be effective in the opposite directions (from the hybrid species into L. idas and L. melissa). More generally in the context of ecological speciation, a greater number of traits might increase the possibility that a hybrid "falls between" the niches represented by the two adaptive peaks occupied by the species or incipient species $[34,35]$. In a relatively simple example involving two traits, hybrids between populations of Mitoura butterflies associated with different host plant species inherit a maladaptive mismatch of traits: hybrid individuals have higher performance on one of the parental hosts, but express an oviposition preference for the other host [36].

However, the importance of multiple traits for ecological speciation in Lycaeides must wait on estimates of historical and contemporary gene flow between pairs of populations and analyses of those estimates in light of variation in ecological and behavioral traits [37]. The inclusion of such comparative data, particularly for a larger suite of populations, would perhaps reveal the influence of a single trait for explaining a majority of the variation in reproductive isolation. It is also possible that a key trait for reproductive isolation remains unstudied in this system. For future studies in this group, it will also be important to sample populations widely throughout the geographic ranges of the focal butterfly species (Figure 1), as dynamics of local adaptation and diversification can be affected by geographic context, particularly proximity to the edge of a range and potentially marginal habitats. Beyond the details of ecological diversification in Lycaeides, our results should generally stress the importance of delving deeper than the traditional "preference-performance relationship" when investigating ecological speciation in herbivorous insects.

\section{Acknowledgments}

The authors would like to thank Bonnie Young and Temba Barber for assistance in rearing caterpillars. This work was supported by the National Science Foundation (IOS1021873 and DEB-1050355 to C. C. Nice; DEB-0614223 and DEB-1050947 to J. A. Fordyce; DEB 1020509 and DEB 1050726 to M. L. Forister; DEB-1011173 to Z. Gompert). C. F. Scholl was supported by the Biology Department at the University of Nevada, Reno.

\section{References}

[1] A. T. Peterson, J. Soberón, and V. Sánchez-Cordero, "Conservatism of ecological niches in evolutionary time," Science, vol. 285, no. 5431, pp. 1265-1267, 1999.

[2] A. Prinzing, W. Durka, S. Klotz, and R. Brandl, "The niche of higher plants: evidence for phylogenetic conservatism," Proceedings of the Royal Society B: Biological Sciences, vol. 268, no. 1483, pp. 2383-2389, 2001.

[3] K. H. Kozak and J. J. Wiens, "Does niche conservatism promote speciation? A case study in North American salamanders," Evolution, vol. 60, no. 12, pp. 2604-2621, 2006.

[4] U. Dieckmann and M. Doebeli, "On the origin of species by sympatric speciation," Nature, vol. 400, no. 6742, pp. 354-357, 1999.

[5] D. Schluter, "Ecology and the origin of species," Trends in Ecology and Evolution, vol. 16, no. 7, pp. 372-380, 2001.

[6] J. Ramsey, H. D. Bradshaw, and D. W. Schemske, "Components of reproductive isolation between the monkeyflowers Mimulus lewisii and M. cardinalis (Phrymaceae)," Evolution, vol. 57, no. 7, pp. 1520-1534, 2003.

[7] D. J. Funk, P. Nosil, and W. J. Etges, "Ecological divergence exhibits consistently positive associations with reproductive isolation across disparate taxa," Proceedings of the National Academy of Sciences of the United States of America, vol. 103, no. 9, pp. 3209-3213, 2006.

[8] K. W. Matsubayashi, I. Ohshima, and P. Nosil, "Ecological speciation in phytophagous insects," Entomologia Experimentalis et Applicata, vol. 134, no. 1, pp. 1-27, 2010.

[9] M. Drès and J. Mallet, "Host races in plant-feeding insects and their importance in sympatric speciation," Philosophical Transactions of the Royal Society B: Biological Sciences, vol. 357, no. 1420, pp. 471-492, 2002.

[10] P. Nosil, "Divergent host plant adaptation and reproductive isolation between ecotypes of Timema cristinae walking sticks," American Naturalist, vol. 169, no. 2, pp. 151-162, 2007.

[11] N. H. Martin and J. H. Willis, "Ecological divergence associated with mating system causes nearly complete reproductive isolation between sympatric Mimulus species," Evolution, vol. 61, no. 1, pp. 68-82, 2007.

[12] C. Wiklund, "The evolutionary relationship between adult oviposition preferences and larval host plant range in Papilio machaon L," Oecologia, vol. 18, no. 3, pp. 185-197, 1975.

[13] S. S. Wasserman and D. J. Futuyma, "Evolution of host plant utilization in laboratory populations of the Southern cowpea weevil, Callosobruchus maculatus fabricius (Coleoptera: Bruchidae)," Evolution, vol. 35, no. 4, pp. 605-617, 1981.

[14] T. P. Craig, J. D. Horner, and J. K. Itami, "Hybridization studies on the host races of Eurosta Solidaginis: implications for sympatric speciation," Evolution, vol. 51, no. 5, pp. 1552-1560, 1997.

[15] P. Nosil, L. J. Harmon, and O. Seehausen, "Ecological explanations for (incomplete) speciation," Trends in Ecology and Evolution, vol. 24, no. 3, pp. 145-156, 2009. 
[16] J. A. Fordyce, C. C. Nice, M. L. Forister, and A. M. Shapiro, "The significance of wing pattern diversity in the Lycaenidae: mate discrimination by two recently diverged species," Journal of Evolutionary Biology, vol. 15, no. 5, pp. 871-879, 2002.

[17] C. C. Nice, J. A. Fordyce, A. M. Shapiro, and R. FfrenchConstant, "Lack of evidence for reproductive isolation among ecologically specialised lycaenid butterflies," Ecological Entomology, vol. 27, no. 6, pp. 702-712, 2002.

[18] L. K. Lucas, J. A. Fordyce, and C. C. Nice, "Patterns of genitalic morphology around suture zones in North American Lycaeides (Lepidoptera: Lycaenidae): implications for taxonomy and historical biogeography," Annals of the Entomological Society of America, vol. 101, no. 1, pp. 172-180, 2008.

[19] M. L. Forister, C. C. Nice, J. A. Fordyce, and Z. Gompert, "Host range evolution is not driven by the optimization of larval performance: the case of Lycaeides melissa (Lepidoptera: Lycaenidae) and the colonization of alfalfa," Oecologia, vol. 160, no. 3, pp. 551-561, 2009.

[20] Z. Gompert, C. C. Nice, J. A. Fordyce, M. L. Forister, and A. M. Shapiro, "Identifying units for conservation using molecular systematics: the cautionary tale of the Karner blue butterfly," Molecular Ecology, vol. 15, no. 7, pp. 1759-1768, 2006.

[21] Z. Gompert, L. K. Lucas, J. A. Fordyce, M. L. Forister, and C. C. Nice, "Secondary contact between Lycaeides idas and L. melissa in the Rocky Mountains: extensive admixture and a patchy hybrid zone," Molecular Ecology, vol. 19, no. 15, pp. 31713192, 2010.

[22] Z. Gompert, J. A. Fordyce, M. L. Forister, A. M. Shapiro, and C. C. Nice, "Homoploid hybrid speciation in an extreme habitat," Science, vol. 314, no. 5807, pp. 1923-1925, 2006.

[23] J. A. Fordyce and C. C. Nice, "Variation in butterfly egg adhesion: adaptation to local host plant senescence characteristics?" Ecology Letters, vol. 6, no. 1, pp. 23-27, 2003.

[24] J. Jaenike, "Host specialization in phytophagous insects," Annual Review of Ecology and Systematics, vol. 21, no. 1, pp. 243-273, 1990.

[25] Z. Gompert, J. A. Fordyce, M. L. Forister, and C. C. Nice, "Recent colonization and radiation of North American Lycaeides (Plebejus) inferred from mtDNA," Molecular Phylogenetics and Evolution, vol. 48, no. 2, pp. 481-490, 2008.

[26] J. P. Klein and M. L. Moeschberger, Survival Analysis: Techniques for Censored and Truncated Data, Springer, New York, NY, USA, 2nd edition, 2003.

[27] T. J. Kawecki and D. Ebert, "Conceptual issues in local adaptation,” Ecology Letters, vol. 7, no. 12, pp. 1225-1241, 2004.

[28] S. Gripenberg, P. J. Mayhew, M. Parnell, and T. Roslin, "A meta-analysis of preference-performance relationships in phytophagous insects," Ecology Letters, vol. 13, no. 3, pp. 383393, 2010.

[29] M. L. Forister, A. G. Ehmer, and D. J. Futuyma, "The genetic architecture of a niche: variation and covariation in host use traits in the Colorado potato beetle," Journal of Evolutionary Biology, vol. 20, no. 3, pp. 985-996, 2007.

[30] P. Nosil and C. P. Sandoval, "Ecological niche dimensionality and the evolutionary diversification of stick insects," PLoS ONE, vol. 3, no. 4, Article ID e1907, 2008.

[31] P. Nosil, T. H. Vines, and D. J. Funk, "Perspective: reproductive isolation caused by natural selection against immigrants from divergent habitats," Evolution, vol. 59, no. 4, pp. 705-719, 2005.

[32] L. Somme, "Adaptations of terrestrial arthropods to the alpine environment," Biological Reviews: Cambridge Philosophical Society, vol. 64, no. 4, pp. 367-407, 1989.
[33] M. L. Forister, Z. Gompert, C. C. Nice, G. W. Forister, and J. A. Fordyce, "Ant association facilitates the evolution of diet breadth in a lycaenid butterfly," Proceedings of the Royal Society B: Biological Sciences, vol. 278, no. 1711, pp. 1539-1547, 2011.

[34] H. A. Orr, "Adaptation and the cost of complexity," Evolution, vol. 54, no. 1, pp. 13-20, 2000.

[35] S. Gavrilets, Fitness landscapes and the origin of species, Princeton University Press, Princeton, NJ, USA, 2004.

[36] M. L. Forister, "Independent inheritance of preference and performance in hybrids between host races of Mitoura butterflies (Lepidoptera: Lycaenidae)," Evolution, vol. 59, no. 5, pp. 1149-1155, 2005.

[37] G. Lu and L. Bernatchez, "Correlated trophic specialization and genetic divergence in sympatric lake whitefish ecotypes (Coregonus clupeaformis): support for the ecological speciation hypothesis," Evolution, vol. 53, no. 5, pp. 1491-1505, 1999. 

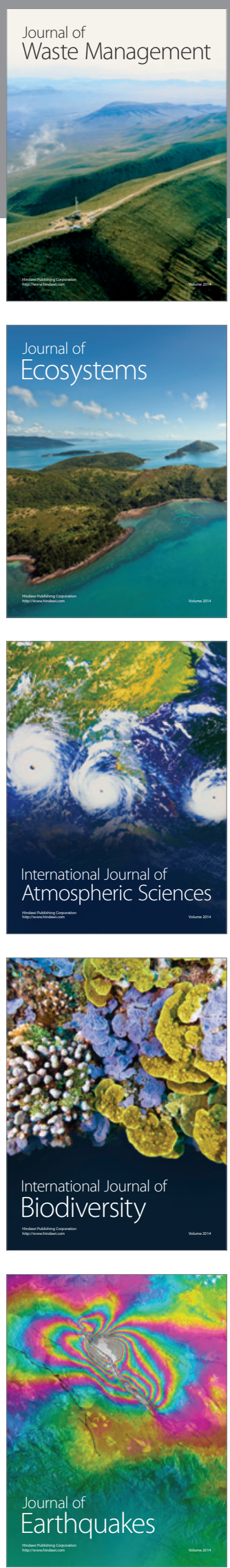
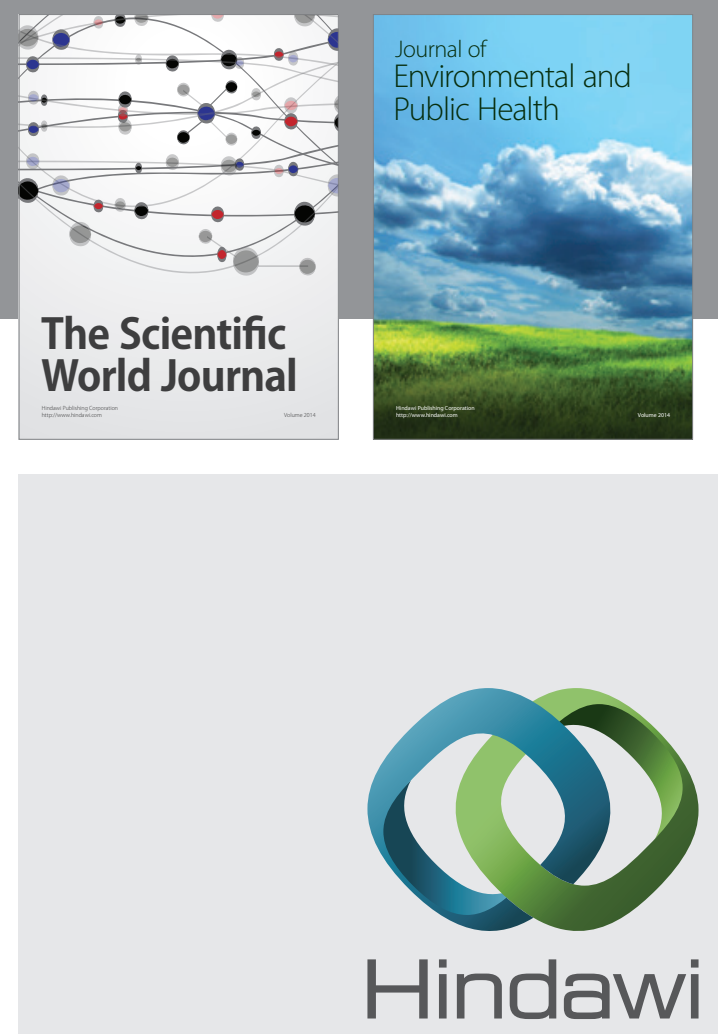

Submit your manuscripts at

http://www.hindawi.com
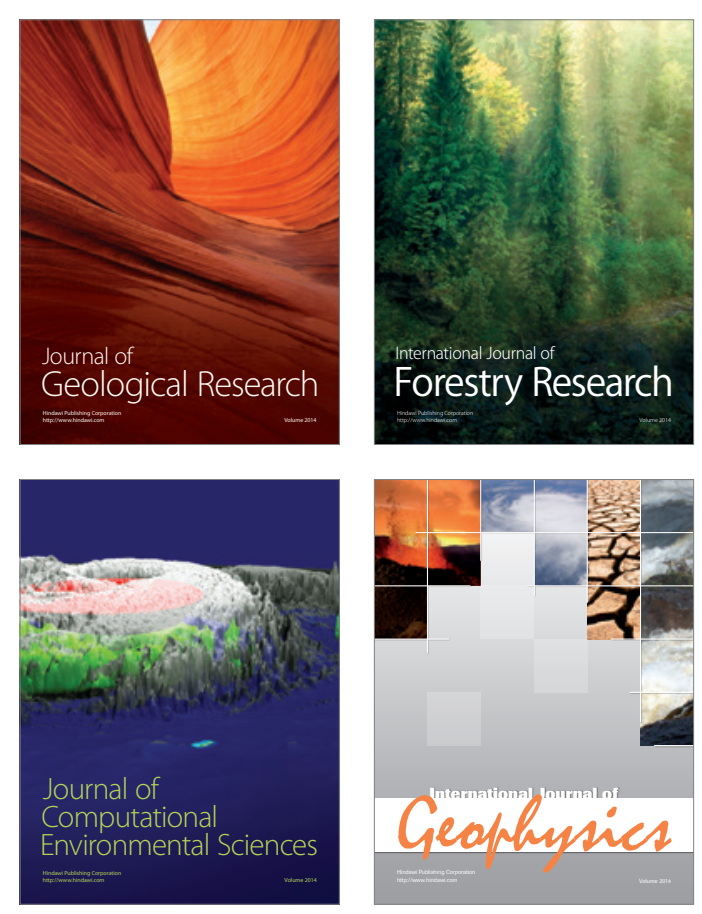
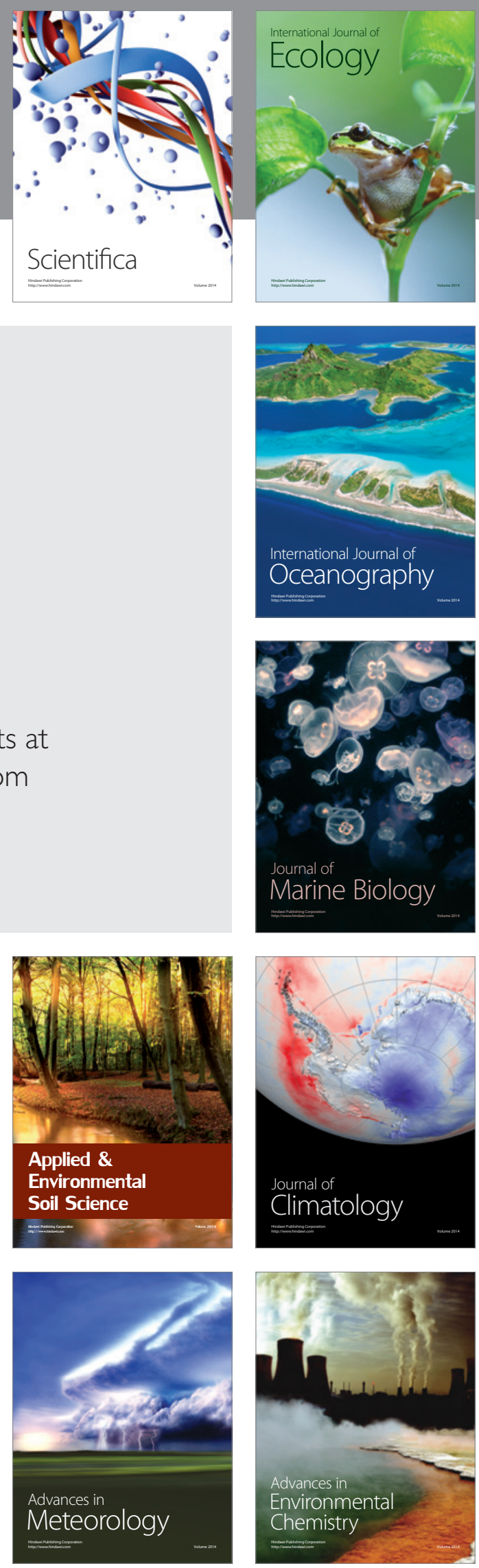